\title{
Peroxisome proliferated-activated receptor $\gamma$ ligand, Pioglitazone, does not prevent hepatic fibrosis in mice
}

\author{
ALAIN DA SILVA MORAIS, JORGE ABARCA-QUINONES, YVES HORSMANS, \\ PETER STÄRKEL and ISABELLE A. LECLERCQ
}

Laboratoire de Gastroentérologie, Université Catholique de Louvain (UCL), Brussels, Belgium

Received June 20, 2006; Accepted August 29, 2006

\begin{abstract}
During hepatic fibrogenesis, quiescent hepatic stellate cells (HSCs) undergo phenotypic transformation into activated matrix-producing cells. This process is recapitulated in primary HSCs cultured on plastic. Based on studies in rats, peroxisome proliferator-activated receptor $\gamma(\operatorname{PPAR} \gamma)$ has been suggested to play a key role in the control of HSC activation. Indeed, in rats, PPAR $\gamma$ expression is depleted in activated HSCs. PPAR $\gamma$ ligands inhibit HSC activation and prevent hepatic fibrosis in vivo. Here we evaluated the impact of PPAR $\gamma$ agonists on hepatic fibrogenesis in mice both in vitro and in vivo. Primary $\mathrm{HSCs}$ from Balb/C mice were cultured with PPAR $\gamma$ ligands Pioglitazone (PGZ) or 15deoxy- $\Delta 12,14$ prostaglandin $\mathrm{J}_{2}\left(15 \mathrm{~d}-\mathrm{PGJ}_{2}\right)$. PPAR $\gamma$ mRNA expression was stable during culture-activation of HSCs. However, PPAR $\gamma$ protein was only found in quiescent HSCs but not in fully activated cells. Exposure of HSCs to PPAR $\gamma$ agonists maintained the expression of PPAR $\gamma$, and transactivated this transcription factor as demonstrated by gelshift assay and by induction of CD36, a PPAR $\gamma$-regulated gene. However, PPAR $\gamma$ ligands did not alter the induction of Collagen-I mRNA or $\alpha$-smooth muscle actin ( $\alpha$-SMA) in cultured HSCs. To test the effect of PPAR $\gamma$ agonist PGZ in vivo, hepatic fibrosis was evaluated in Balb/C or C57BL6/J mice treated with $\mathrm{CCl}_{4}$ (three times a week for 4 weeks; or corn oil for controls), and fed a normal or a PGZ-supplemented diet $(0.01 \% w t / w t)$. PGZ treatment was associated with
\end{abstract}

Correspondence to: Dr Isabelle Leclercq, Laboratoire de Gastroentérologie, Université Catholique de Louvain, GAEN 53/79, Avenue Mounier 53, B-1200 Brussels, Belgium

E-mail: isabelle.leclercq@gaen.ucl.ac.be

Abbreviations: $15 \mathrm{~d}_{-} \mathrm{PGJ}_{2}, 15$-deoxy- $\Delta \mathbf{1 2 , 1 4}$ prostaglandin $\mathrm{J}_{2} ; \alpha$-SMA, $\alpha$-smooth muscle actin; Col- $\alpha$ I, Collagen- $\alpha$ I; DMEM, Dulbecco's modified Eagle's medium; DMSO, dimethyl sulfoxide; ECM, extracellular matrix; FBS, foetal bovine serum; HSC, hepatic stellate cell; PGZ, Pioglitazone; PPAR $\gamma$, peroxisome proliferatoractivated receptor $\gamma$

Key words: PPAR $\gamma$, hepatic stellate cell, Pioglitazone, hepatic fibrogenesis, mouse increased serum adiponectin concentrations but did not decrease the severity of hepatic fibrosis induced by $\mathrm{CCl}_{4}$. Our data demonstrate that, although having anti-fibrotic properties in rats, PPAR $\gamma$ agonists do not prevent activation of HSCs in vitro, nor hepatic fibrogenesis in vivo in mice.

\section{Introduction}

Liver fibrosis is the consequence of most types of chronic liver disease and results from excess deposition of extracellular matrix (ECM) components generated mainly by hepatic stellate cells (HSCs) $(1,2)$. In the normal liver, HSCs play a key role in the storage and transport of vitamin A (3). In response to liver injury, or spontaneously when cultured on plastic, these cells activate or trans-differentiate into myofibroblasticlike cells, acquiring contractile, proliferative, pro-inflammatory and fibrogenic properties $(4,5)$. Most of the anti-fibrotic treatments currently under evaluation aim at inhibiting the activation of HSCs $(6,7)$. The identification of key cytokines, transcription factors and molecular mechanisms controlling HSC activation is believed to lead to pathophysiologicalbased strategies to treat liver fibrosis.

Peroxisome proliferator-activated receptor $\gamma(\operatorname{PPAR} \gamma)$, a member of the steroid/retinoid nuclear hormone receptor superfamily of ligand-activated transcription factors (8), has been proposed as a potential molecular target for inhibition of HSC trans-differentiation. PPAR $\gamma$ has been shown to be expressed in quiescent HSCs and its expression and activity decreased during HSC activation in vitro and in vivo in rats $(6,7,9)$. The treatment of rat HSCs with ligands for PPAR $\gamma$ prevented their activation in vitro. In addition, forced expression of PPAR $\gamma$ in culture-activated HSCs by means of adenoviral transfection has been shown to revert their phenotype to that of quiescent cells (10-12).

In vivo, treatment of rats with thiazolidinediones drugs [Pioglitazone (PGZ) or rosiglitazone], which are synthetic ligands for PPAR $\gamma$, prevent hepatic fibrosis resulting from chronic toxic injury or bile duct ligation $(6,7,13)$. Despite this potent preventive effect, PGZ has limited efficacy in the treatment of pre-established hepatic fibrosis. Indeed, we recently published that PGZ halts the progression of hepatic fibrosis only when the treatment is administered early in the course of toxic or metabolic disease (14).

PPAR $\gamma$ activation plays a role in various physiological and pathophysiological events, including the stimulation of 
adipocyte differentiation, the response to insulin and the regulation of lipid metabolism as well as the maturation of monocyte/macrophages and the control of inflammatory reaction (15). Therefore, besides direct action on HSCs, PPAR $\gamma$ stimulation may also interfere with the fibrotic process via modulation of adipocytokine production or as a consequence of its anti-inflammatory properties. The use of genetically modified mice is therefore a good tool to explore the implication of such additional mechanisms for the antifibrotic effect of PPAR $\gamma$ agonists. As a prerequisite to such studies, the anti-fibrotic properties of PPAR $\gamma$ agonists need to be evaluated in mice.

Thus we analysed the regulation of PPAR $\gamma$ expression during the culture activation of mouse primary HSCs as well as the impact of PPAR $\gamma$ agonist on matrix production and HSC activation. We also examined the effect of treatment with the PPAR $\gamma$ agonist PGZ on $\mathrm{CCl}_{4}$-induced hepatic fibrosis in mice in vivo. Surprisingly, and contrasting with observations in rats, PGZ did not prevent hepatic fibrosis in mice. Moreover, although we found PPAR $\gamma$ to be expressed in quiescent HSCs and downregulated during their activation, PPAR $\gamma$ agonists did not prevent collagen I expression nor myofibroblastic trans-differentiation in cultured murine HSCs.

\section{Materials and methods}

Animal studies. Female Balb/C and C57BL6/J mice, were obtained from Elevage Janvier (Le Genest Saint Isle, France). All animals were kept in a temperature- and humiditycontrolled environment in a 12-h light-dark cycle. They were allowed free access to water and food. The animals were handled according to the guidelines for humane care for laboratory animals established by the Université Catholique de Louvain (UCL), and the study protocol was approved by the local ethics committee. To examine the effect of Pioglitazone (PGZ) on hepatic fibrosis, 8-week-old Balb/C mice were randomly divided into 4 experimental groups $(n=5$ per group). Mice were injected with $\mathrm{CCl}_{4}(400 \mu \mathrm{l} / \mathrm{kg}$ body weight in corn oil) intra-peritoneally three times a week for 4 weeks and fed a standard powdered diet (Pavan Service Carfil Quality, Oud-Thurnout, Belgium) $\left(\mathrm{CCl}_{4}\right.$ group) or a PGZ-supplemented diet $\left(\mathrm{CCl}_{4}+\mathrm{PGZ}\right.$ group). The PGZsupplemented diet was prepared by mixing PGZ (Takeda Chemical Industries, Osaka, Japan) with the powdered standard diet to obtain a $0.01 \%$ Pioglitazone diet $(w t / w t)$. As controls, mice received intra-peritoneal injections of corn oil (3 times/week for 4 weeks) and were fed a normal diet (control group) or the PGZ-supplemented diet (PGZ group). A similar experiment was repeated on the female C57BL6/J mice.

At the time of sacrifice $(48 \mathrm{~h}$ after the last injection of $\mathrm{CCl}_{4}$ ), blood was collected by cardiac puncture and the liver and abdominal subcutaneous fat rapidly excised. Part of the liver was fixed in $4 \%$ formalin, embedded in paraffin and used for histological analyses. The remaining liver and the subcutaneous adipose tissue were snap frozen in liquid nitrogen and kept at $-80^{\circ} \mathrm{C}$ until use.

Isolation and characterization of hepatic stellate cells. Primary HSCs were isolated from female Balb/C mice by in situ pronase-collagenase digestion of the liver followed by density centrifugation on a Histodenz gradient (11\%) as described by others (16). Five mouse livers were perfused for each isolation. After isolation, the cells were re-suspended in Dulbecco's modified Eagle's medium (DMEM; Invitrogen, Merelbeke, Belgium) supplemented with $20 \%$ foetal bovine serum (FBS, Invitrogen), 100 units/ml penicillin and $100 \mu \mathrm{g} /$ $\mathrm{ml}$ streptomycin (Invitrogen). Primary HSCs were cultured in cell culture dishes at $37^{\circ} \mathrm{C}$ in a humidified atmosphere with $5 \% \mathrm{CO}_{2}$ and $95 \%$ air. At day 1, the medium was removed and replaced by DMEM supplemented with 5\% FBS.

The purity of the cultures was evaluated by examining the characteristic stellate shape of the cells with phase-contrast microscopy and by the presence of lipid droplets by autofluorescence using an excitation light of $320 \mathrm{~nm}$. After the first replacement of medium (day 1), purity was $>90 \%$. At day 9 the cells were passaged by treatment with $5 \mathrm{ml}$ of Trypsin-EDTA $0.5 \mathrm{X}$ (Invitrogen) per dish for $7 \mathrm{~min}$ at $37^{\circ} \mathrm{C}$. After addition of $5 \mathrm{ml}$ of DMEM with $20 \% \mathrm{FBS}$, the cells were collected and washed twice in PBS, and seeded in DMEM supplemented with 5\% FBS.

HSC treatment. To analyse the effect of PPAR $\gamma$ agonists on HSC biology, HSCs were incubated with DMEM supplemented with 5\% FBS containing PGZ $10 \mu \mathrm{M}$ (Takeda Chemical Industries), or vehicle (DMSO). In separate experiments, cells were incubated with the most potent PPAR $\gamma$ activator 15deoxy- $\Delta 12,14$ prostaglandin $\mathrm{J}_{2}\left(15 \mathrm{~d}-\mathrm{PGJ}_{2}\right) 10 \mu \mathrm{M}$ (Sigma Aldrich, ref. no. D8440, Bornem, Belgium) or vehicle (ethanol $0.5 \%$ ). Treatment was initiated at day 1 or day 3 after plating as indicated in the Results section. Medium was renewed every 2 days and the cells were passaged at day 9 .

Total RNA extraction. Total RNA was extracted from cultured HSCs or from liver or adipose tissue using the TriPure isolation reagent kit (Roche Diagnostics Belgium, Vilvoorde). cDNA was prepared by reverse transcription of $1 \mu \mathrm{g}$ total hepatic RNA using random primers and M-MLV (Moloney murine leukemia virus) reverse transcriptase (Gibco BRL, Merelbeke, Belgium). To assess the expression of PPAR $\gamma$ mRNA in HSCs during culture conditions, gene amplification was conducted using TaqDNA polymerase (Amersham Biosciences, Diegem, Belgium) and primers (sense, 5'-aagag atcacagagtatgcc-3' and anti-sense, 5'-cttcacagcaaactcaaac-3'). This expression was compared to that of Ribosomal protein L19 (RPL19) RNA (primers: sense, 5'-agtatgctcaggcttcagaa3'; and anti-sense, 5'-gcaggtctaagaccaaggaa-3') serving as control (17). The cycle conditions were $94^{\circ} \mathrm{C}$ for $5 \mathrm{~min}, 94^{\circ} \mathrm{C}$ for $1 \mathrm{~min}, 56^{\circ} \mathrm{C}$ for $1 \mathrm{~min}$ and $72^{\circ} \mathrm{C}$ for $1 \mathrm{~min}$ (30 cycles) and then $72^{\circ} \mathrm{C}$ for $10 \mathrm{~min}$.

To quantify gene expression, real-time PCR analysis was carried out with the GeneAmp 5700 sequence detection system and software (Applied Biosystems, Den Ijssel, Netherlands) using SYBR-Green for detection. RPL19 RNA was chosen as an invariant standard. Adiponectin, CD36, Collagen- $\alpha$ I (Col- $\alpha \mathrm{I})$, PPAR $\gamma$ total and RPL19 primers were designed using the Primer Express design software (Applied Biosystems). The following primers were used: adiponectin: sense, 5'-gcagagatggcactcctgga-3' and anti-sense, 5'-cccttcag ctcctgtcattcc-3'; CD36: sense, 5'-tccagccaatgcetttgc-3' and anti-sense, 5'-ttctgcactgaaaaagtaatctcca-3'; Col- $\alpha$ I: sense, 5'- 
ttcacctacagcacgcttgt-3' and anti-sense, 5'-tcatcgaatacaaaacca ccaaga-3'; PPAR $\gamma$ total: sense, 5'-ctgctcaagtatggtgtccatga-3' and anti-sense, 5'-tgaataaagatggagtcctcatctca-3'; and RPL19: sense, 5'-gaaggtcaaagggaatgtgttca-3' and anti-sense, 5'acaagctgaaggcagacaagg-3'. cDNA derived from adipose tissue or the liver was used to prepare standard dilution curves. PCR reactions were performed according to the standardized thermal profile of the system previously set by the manufacturer. All tissue and standard curve samples were run in duplicate at the same time in a single 96-well reaction plate (MicroAmp Optical, Applied Biosystems) using the appropriate primers. Results are expressed as relative gene expression (RGE) using the $\Delta \mathrm{Ct}$ method (User bulletin 2, Applied Biosystems).

Histology, immunohistochemistry and immunocytochemistry. Mouse livers were fixed in $4 \%$ neutral buffered formalin overnight, processed to paraffin blocks, sectioned, and stained with hematoxylin and eosin or sirius red (to visualize collagen deposition) by using standard techniques. Immunodetection for $\alpha$-smooth muscle actin ( $\alpha$-SMA) was performed as previously described (18), using mouse monoclonal anti- $\alpha$-SMA (Clone $1 \mathrm{~A} 4 ; 1: 100)$ and the EnVision Dako mouse as secondary antibody. All reagents were from DakoCytomation (Via Real, USA), unless indicated otherwise.

For immunocytochemistry experiments, the cells were seeded on plastic Thermanox ${ }^{\mathrm{TM}}$ coverslips $(25 \mathrm{~mm}$ in diameter, Nunc, Rochester, NY, USA). At determined times (ranging from 1 to 12 days) the coverslips were washed once in PBS and the cells were fixed by immersion in formaldehyde $4 \%$ at $4{ }^{\circ} \mathrm{C}$ for $5 \mathrm{~min}$. Endogenous peroxidases were inhibited by incubating the coverslips in methanol with $0.1 \% \mathrm{H}_{2} \mathrm{O}_{2}$. After immersion in PBS containing 10\% normal goat serum for $20 \mathrm{~min}$, the coverslips were incubated with either mouse monoclonal anti- $\alpha$-SMA antibody (1:300) (Clone 1A4), mouse monoclonal anti-Desmin antibody (1:500) (Clone D33), rabbit polyclonal anti-GFAP antibody (1:1000) (Clone 6F2) or anti-PPAR $\gamma$ antibody (1:50) (H-100; Santa-Cruz, Heidelberg, Germany) overnight at $4^{\circ} \mathrm{C}$. After washing in PBS, the coverslips were incubated with the appropriate peroxidaseconjugated secondary antibody at room temperature for $1 \mathrm{~h}$. Peroxidase activity was revealed with 3-amino-9-ethylcarbazole (DakoCytomation). Slides were then counter-stained in haematoxylin and eosin and examined under the microscope. The percentage of positive cells was determined by counting the stained cells versus the total number of cells.

Preparation of cell lysates and nuclear extracts. Lysates for Western blot analyses were obtained by incubating the cells in $500 \mu \mathrm{l}$ of buffer containing $150 \mathrm{mM} \mathrm{NaCl} ; 1.5 \mathrm{mM}$ $\mathrm{MgCl}_{2} ; 10 \%$ Glycerol; $0.1 \%$ Triton X-100; 1 mM EGTA; $50 \mathrm{mM}$ HEPES and $2 \mu \mathrm{g} / \mathrm{ml}$ of aprotinin and of leupeptin; for $5 \mathrm{~min}$ at $37^{\circ} \mathrm{C}$. The resulting lysates were collected and clarified by centrifugation (10 $\mathrm{min}$ at $12,000 \mathrm{x} \mathrm{g}$ ). Nuclear extracts were prepared using the nuclear extract kit (Active Motif, Rixensart, Belgium), and stored at $-80^{\circ} \mathrm{C}$. The protein contents were determined using a BCA protein assay with serum albumin as a standard (Pierce Chemical, Rockford, IL, USA).
Western blotting. Proteins from HSC lysates were separated by SDS-PAGE and transferred onto PVDF transfer membranes (PolyScreen). Fifty-five micrograms of proteins were loaded for the detection of PPAR $\gamma$ and $\alpha$-SMA. Homogenates from adipose tissue were used as positive controls for PPAR $\gamma$ Western blots. The membranes were then stripped (Pierce's restore Western blot stripping, Milwaukee, WI, USA) and reprobed with $ß$-actin antibody to assess equal protein load. The following antibodies and conditions were used: a rabbit polyclonal anti-PPAR $\gamma$ antibody (H-100; Santa-Cruz, Heidelberg, Germany; 1:1000; overnight), a mouse monoclonal anti- $\alpha$-SMA antibody (Clone 1A4, DakoCytomation, 1:5000; $1 \mathrm{~h}$ ); a mouse monoclonal anti$ß$-actin antibody (Clone AC-15, Sigma, Heidelberg, Germany; $1: 80.000 ; 1 \mathrm{~h}$ ); secondary peroxidase-conjugated AffiniPure goat anti-mouse or goat anti-rabbit antibodies (Jackson ImmunoResearch, Cambridgeshire, UK) for $\beta$-actin and $\alpha$-SMA or PPAR $\gamma$, respectively. The antigen-antibody reaction was visualized using the Western lightning chemiluminescence reagent plus (PerkinElmer) detection system followed by exposure of the membranes to a Kodak X-Omat Blue XB film. The quantification of immune-reactive proteins was obtained by densitometry using the Gel Doc 2000 device and software (Bio-Rad, Nazareth, Belgium).

Electrophoretic mobility shift assays (EMSA). Ten micrograms of nuclear proteins were incubated for $20 \mathrm{~min}$ on ice in binding buffer (Tris- $\mathrm{HCl} 10 \mathrm{mM} \mathrm{pH} \mathrm{7.5,} \mathrm{NaCl} 50 \mathrm{mM}$, EDTA $1 \mathrm{mM}$, DTT $1 \mathrm{mM}$, glycerol 5\%) containing $1 \mu \mathrm{g}$ poly $(\mathrm{dI}-\mathrm{dC})(2 \mu \mathrm{g} / \mu \mathrm{l})$ and $0.5 \mathrm{ng}$ of $\gamma-32 \mathrm{P}$ end-labelled double-stranded oligonucleotides $(20.000 \mathrm{cpm})$. Nuclear extracts $(5 \mu \mathrm{g})$ from COS-7 transfected with PPAR $\gamma$ (Active Motif, Rixensart, Belgium) were used as positive control. DNA protein complexes were separated by electrophoresis (200 V , $2 \mathrm{~h}$ ) on a 5\% polyacrylamide gel (29:1 cross-linking) in a $1 \mathrm{X}$ TBE buffer $(88 \mathrm{mmol} / \mathrm{l}$ TRIS, $88 \mathrm{mmol} / \mathrm{l}$ boric acid, $2 \mathrm{mmol} / \mathrm{l}$ EDTA). Gels were dried and exposed to a Kodak BioMax MS Film (Amersham International plc, Little Chalfont, UK) for $24 \mathrm{~h}$. Pre-annealed chromatographypurified double-stranded oligonucleotides containing the peroxisome-proliferator-responsive element (PPRE) (5'-TGC ACATTTCACCCAGAGAGAAGGGATTGA-3') were used as a probe (7). To confirm the identity of the protein/DNA binding, a supershift analysis was performed as follows: NE were pre-incubated with $2 \mu \mathrm{l}$ of specific antibody $(2 \mu \mathrm{g} / \mu \mathrm{l})$ (PPAR $\gamma \mathrm{H}-100$; Santa-Cruz) for $20 \mathrm{~min}$ on ice. Then the binding buffer, $\mathrm{dI}-\mathrm{dC}$ and probe were added and the mixture was incubated for a further $20 \mathrm{~min}$ on ice.

Biochemical assays. The level of adiponectin in serum was determined using a mouse adiponectin RIA kit (Linco Research, MO, USA). The hydroxyproline content was determined on liver samples hydrolyzed in $5 \mathrm{ml} 6 \mathrm{M} \mathrm{HCl}$ at $110^{\circ} \mathrm{C}$ for $18-24 \mathrm{~h}$ as previously reported (19) using hydroxyproline $40 \mu \mathrm{g} / \mathrm{ml}$ (Sigma Aldrich) as a standard.

Statistical analysis. Results are expressed as mean \pm standard deviation (SD). Statistical differences between groups were tested using one way analysis of variance (ANOVA). Statistical significance was assumed for p values $<0.05$. 
A

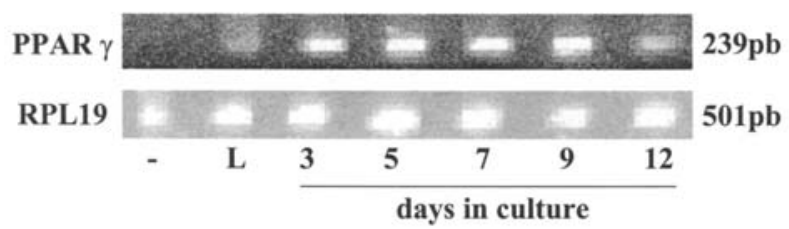

B

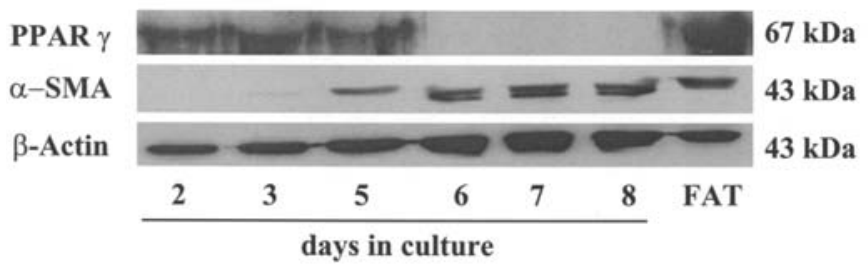

Figure 1. PPAR $\gamma$ mRNA and protein expression in cultured mouse primary HSC. (A) Expression of PPAR $\gamma$ and RPL19 (housekeeping gene) mRNA evaluated by PCR as described in the Materials and methods section. cDNA derived from RNA extracted from whole liver (L). Reaction mixture in which cDNA was omitted served as negative control (-). (B) Representative Western blot showing the evolution of PPAR $\gamma$ protein expression in HSC during culture. The initial blot has been stripped and reprobed with $\alpha$-smooth muscle actin ( $\alpha$-SMA) and $\beta$-actin antibodies to assess for HSC activation and equivalence of protein loading, respectively. Protein extracted from adipose tissue (FAT) served as positive control for PPAR $\gamma$ protein expression. Primary mouse (Balb/c) HSC were cultured in DMEM supplemented with $5 \%$ FBS, and cell lysates were prepared at the indicated time points.

\section{Results}

PPAR expression in cultured HSCs. We evaluated the expression of PPAR $\gamma$ in quiescent HSCs (day 3) and its regulation during activation of HSCs under culture conditions. Quiescent HSCs and HSCs cultured for up to 9 days expressed PPAR $\gamma$ mRNA at similar levels (Fig. 1A). After 12 days in culture (i.e. after one passage at day 9), we observed a decreased expression of PPAR $\gamma$ mRNA (Fig. 1A). The decreased expression of PPAR $\gamma$ mRNA after long-term culture and passage has been confirmed by quantification of PPAR $\gamma$ transcripts by real-time PCR (not shown). We then evaluated the expression of PPAR $\gamma$ protein by Western blotting. The presence of PPAR $\gamma$ protein was readily demonstrated in HSCs cultured for up to 5 days, but the protein was no longer detected in HSCs cultured for longer periods (6, 7 or 8 days) (Fig. 1B). As demonstrated by $\alpha$-SMA expression, the loss of PPAR $\gamma$ protein detection occurred when HSCs underwent activation into myofibroblasts. Thus, after 5 days in culture, there was a marked decrease in PPAR $\gamma$ protein expression, while transcript expression was maintained for up to 9 days, suggesting that the inhibition of protein occurs first at the post-transcriptional then at the transcriptional level during the culture activation of HSCs.

Functionality of PPAR in cultured HSCs. To assess whether the PPAR $\gamma$ transcription factor is functionally active in HSCs, we analysed the mRNA expression of a PPAR $\gamma$-regulated
A
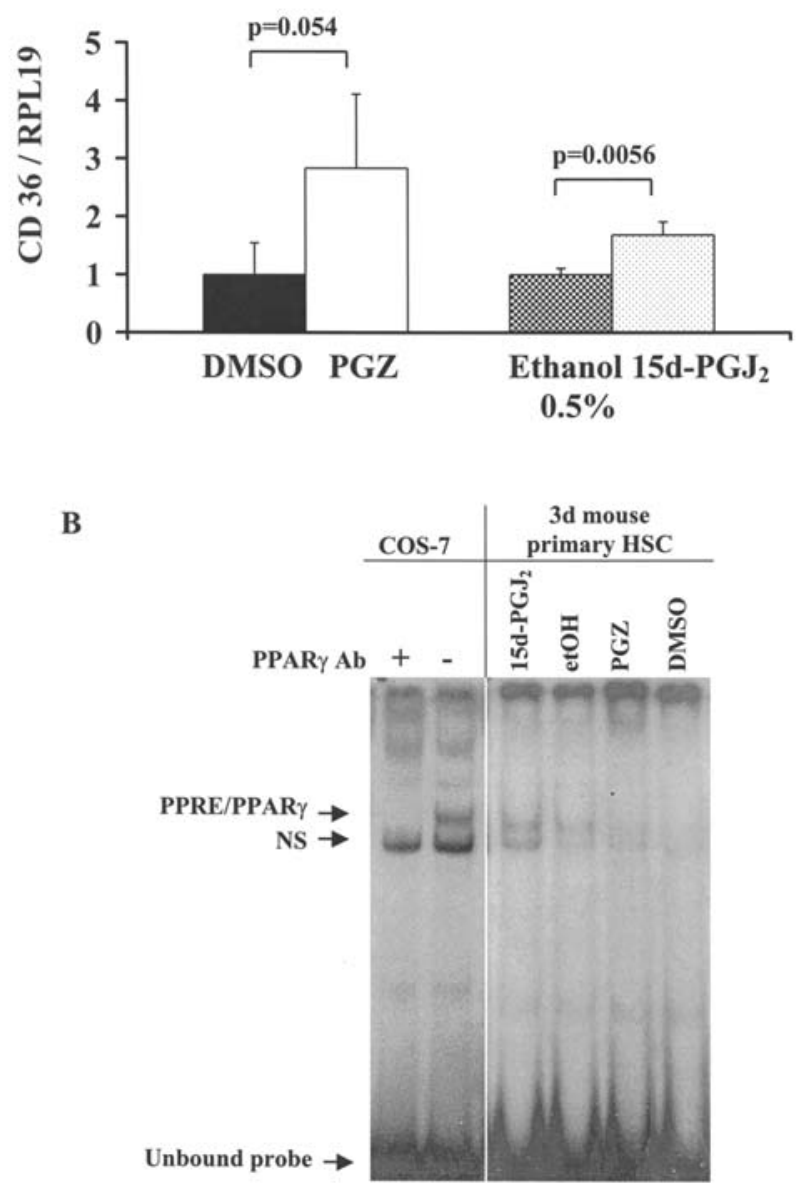

Figure 2. Pioglitazone induces the expression of the PPAR $\gamma$-regulated CD36 gene and PPRE binding in cultured HSC. (A) Bar graphs represent the level of CD36 mRNA expression as determined by real-time PCR in primary HSC from Balb/C mouse livers cultured from day 1 to day 7 in DMEM supplemented with Pioglitazone (PGZ) $10 \mu \mathrm{M}$ or DMSO (vehicle), or in the presence of $15 \mathrm{~d}-\mathrm{PGJ}_{2} 10 \mu \mathrm{M}$ or ethanol $0.5 \%$ (vehicle). Results have been normalised to the expression of RPL19 mRNA as an invariant control. Data are expressed as mean \pm SD on $n=10$ culture dishes from 2 different cell preparations. $\mathrm{p}$ values are given for PPAR $\gamma$ agonist-treated cells versus their respective controls. (B) Electromobility shift assay and supershift on nuclear fractions of 3-day-old HSC exposed for $2 \mathrm{~h}$ to PGZ $(10 \mu \mathrm{M})$ or DMSO as vehicle, or to $15 \mathrm{~d}-\mathrm{PGJ}_{2}$ or ethanol as vehicle. Nuclear extracts from PPAR $\gamma$ transfected COS-7 cells were used as positive control. (NS, non specific bands).

gene, CD36, in cultured HSCs by real-time PCR. Primary HSCs have been cultured from day 1 to 7 in DMEM supplemented with PGZ $10 \mu \mathrm{M}$, or DMSO (vehicle) or in the presence of the potent PPAR $\gamma$ ligand $15 \mathrm{~d}_{-} \mathrm{PGJ}_{2} 10 \mu \mathrm{M}$, or ethanol $0.5 \%$ used as vehicle. The CD36 mRNA expression was increased in cells treated with PPAR $\gamma$ agonists (Fig. 2A), suggesting the functionality of PPAR $\gamma$ in cultured HSCs. To confirm these results we performed EMSA using a typical peroxisome proliferator responsive element (PPRE) as target oligonucleotide. After 3 days in culture, HSCs were exposed for $2 \mathrm{~h}$ to PGZ $(10 \mu \mathrm{M}), 15 \mathrm{~d}-\mathrm{PGJ}_{2}(10 \mu \mathrm{M})$ or vehicle (DMSO or ethanol, respectively). Nuclear proteins were then extracted and subjected to a gel shift assay. Nuclear extracts from PPAR $\gamma$-transfected COS-7 cells served as positive controls. As shown in Fig. 2B, a retarded band was observed in PGZ- compared to DMSO-treated HSCs. Similarly, the 


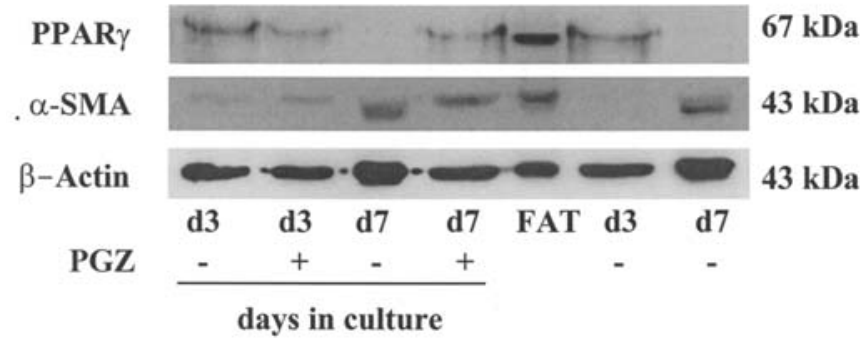

Figure 3. Effect of PGZ treatment on PPAR $\gamma$ and $\alpha$-SMA protein expression in murine HSC. Representative Western blot for PPAR $\gamma$ in HSC cultured from day 1 to day 7 in DMEM containing 5\% FBS supplemented with PGZ $10 \mu \mathrm{M}(+)$ or DMSO as vehicle (-). Cell lysates were prepared at day 3 or at day 7. The initial blot has been stripped and reprobed with $\alpha$-smooth muscle actin ( $\alpha$-SMA) and $\beta$-actin antibodies. Proteins extracted from adipose tissue (FAT) served as positive control.

retarded band was of stronger intensity in $15 \mathrm{~d}-\mathrm{PGJ}_{2}$-treated cells than in the ethanol controls. To note, a PPRE binding complex was seen in ethanol- but not in DMSO-treated cells. Supershift assay confirmed the presence of PPAR $\gamma$ in the protein/DNA retarded complex.

Effect of PPAR ligands on PPAR protein expression in cultured HSCs. To evaluate the impact of PPAR $\gamma$ ligand on $\operatorname{PPAR} \gamma$ protein expression in our culture system, murine primary HSCs were cultured with PGZ $(10 \mu \mathrm{M})$, or vehicle $24 \mathrm{~h}$ after seeding. Lysates were prepared at day 3 and day 7, and used for Western blot analysis. At day 3, PPAR $\gamma$ protein was expressed at similar intensity in HSCs whether cultured in the presence or in the absence of PGZ (Fig. 3). At day 7, $\operatorname{PPAR} \gamma$ protein was not detected in control cells. However, culture of HSCs in the presence of PGZ was associated with the persistence of PPAR $\gamma$ protein expression (Fig. 3). This treatment did not affect the trans-differentiation of the cells as confirmed by the $\alpha$-SMA protein expression in the different groups of treated HSCs (Fig. 3).

Effects of PPAR agonists on HSC activation. To assess the effects of PPAR $\gamma$ activation on fibrogenesis in vitro, we evaluated Collagen-I mRNA expression by real-time PCR in HSCs cultured for 4 days in the presence of PGZ $(10 \mu \mathrm{M})$ or $15 \mathrm{~d}_{-\mathrm{PGJ}_{2}}(10 \mu \mathrm{M})$. As shown in Fig. $4 \mathrm{~A}$ and $\mathrm{B}$, treatment with PGZ or $15 \mathrm{~d}_{-} \mathrm{PGJ}_{2}$ from day 3-7 did not affect the expression of Collagen-I mRNA, relative to vehicle-treated cells. Similarly, no change in Collagen-I mRNA was seen in HSCs exposed to PPAR $\gamma$ ligands as early as $24 \mathrm{~h}$ after seeding (from day 1-5).

As expected, the proportion of HSCs expressing $\alpha$-SMA increased progressively with time in culture so that 22 and $76 \%$ of HSCs were $\alpha$-SMA positive at day 3 and 7 , respectively. To evaluate the impact of PGZ treatment on HSC activation, we incubated the cells with PGZ $(10 \mu \mathrm{M})$ or DMSO $24 \mathrm{~h}$ after plating and evaluated the number of $\alpha$-SMA expressing cells at day 3 and day 7. As shown in Fig. 4C, the percentage of HSCs expressing the $\alpha$-SMA protein was similar in the PGZ and the DMSO-treated HSCs, demonstrating that PGZ does not prevent the spontaneous activation of murine HSCs in culture.

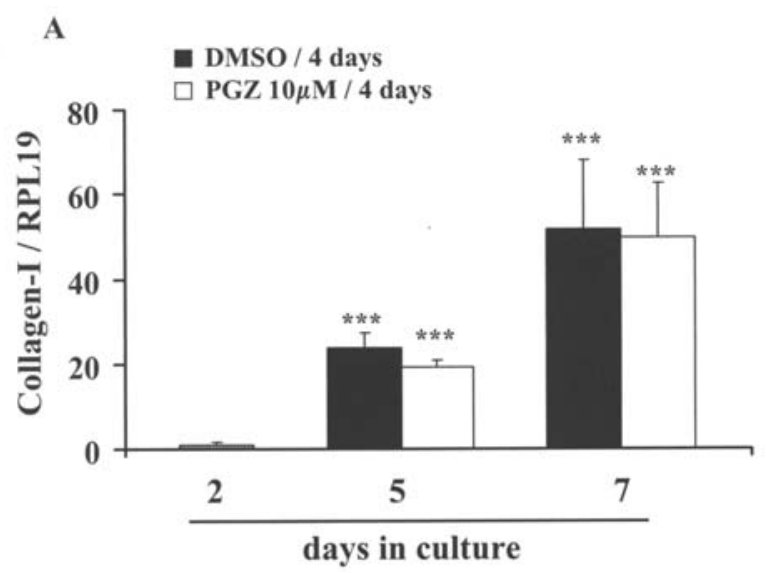

B

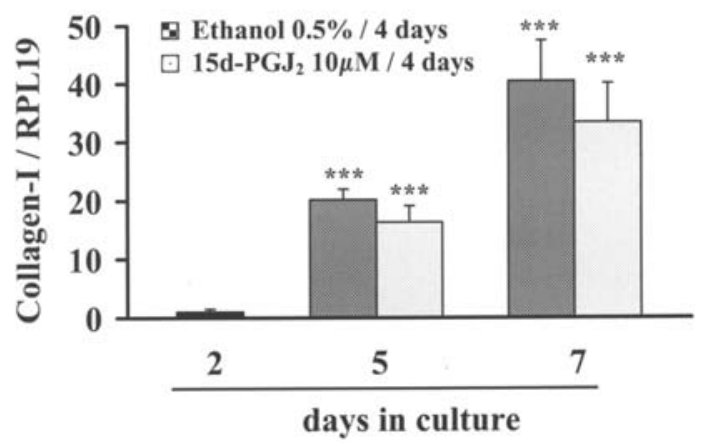

$\mathbf{C}$

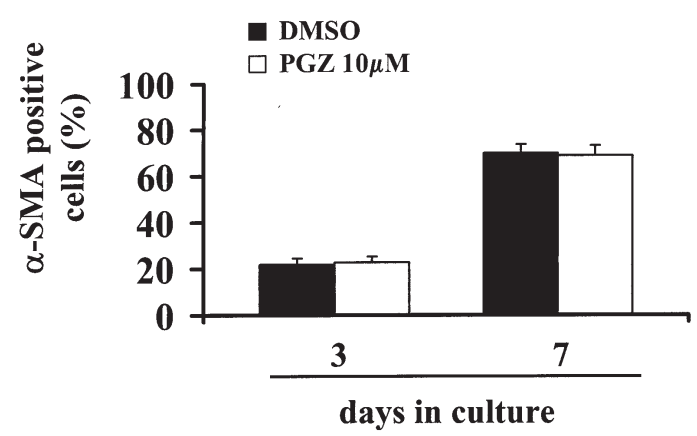

Figure 4. PPAR $\gamma$ ligands PGZ and $15 \mathrm{~d}_{-} \mathrm{PGJ}_{2}$ do not alter Collagen-I mRNA expression or $\alpha$-SMA expression during culture activation of murine HSC. Graph bars represent collagen mRNA expression quantitated by real-time PCR in primary HSC cultured in the presence of (A) PGZ $10 \mu \mathrm{M}$ (open

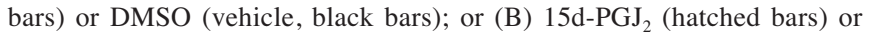
ethanol $0.5 \%$ (vehicle, grey bars). Cells were exposed to PPAR $\gamma$ ligand or vehicles for 4 days (i.e. from day 1-5, or from day 3-7). Individual values represent the ratio of Collagen-I mRNA to RPL19 mRNA. The value obtained for cDNA derived from 2-day-old untreated HSC has been arbitrarily set at one. Data are mean \pm SD (arbitrary units) for $n=10$ dishes per group, from 3 different cell preparations. (C) $\alpha$-SMA immunopositive cells (\% of total cell number) in HSC cultured in the presence of PGZ $10 \mu \mathrm{M}$ (open bars) or DMSO (vehicle, black bars) for 3 or 7 days. ${ }^{* * *} \mathrm{p}<0.001$ compared to 2-day-old, untreated HSC. There is no significant difference between PGZ- and DMSO-treated cells, nor between $15 \mathrm{~d}_{-} \mathrm{PGJ}_{2}$ - and ethanol-treated HSC.

Effect of PPAR $\gamma$ agonist PGZ on hepatic fibrogenesis in vivo. To determine whether PGZ has anti-fibrotic properties in vivo in mice, we induced hepatic fibrosis in female Balb/C or 


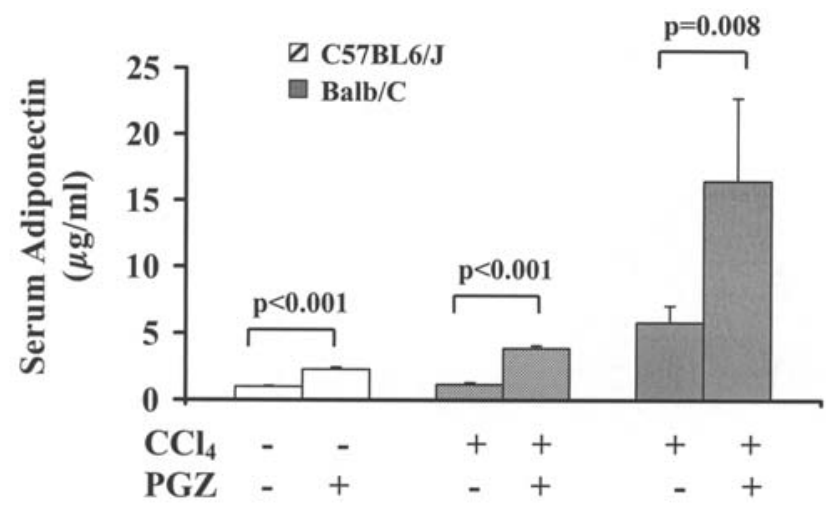

Figure 5. PGZ administered as a food-supplemented diet induces adiponectin in C57BL6/J and Balb/C mice. Serum adiponectin levels in mice treated with $\mathrm{CCl}_{4}$ (400 $\mu \mathrm{l} / \mathrm{kg}$ body weight, 3 times a week) for 4 weeks (C57BL6/J mice, hatched bars; Balb/C mice, grey bars) or vehicle (C57BL6/J mice, open bars) and fed the PGZ-supplemented diet $(+)$ or the control diet (-). Data are expressed as mean $\pm \mathrm{SD}$ in $\mu \mathrm{g} / \mathrm{ml}$ for $\mathrm{n}=5$ per group.

C57BL6/J mice by repeated intra-peritoneal injections of $\mathrm{CCl}_{4}$ for 4 weeks. During this period, mice were fed a PGZsupplemented diet $(0.01 \% w t / w t)(\mathrm{n}=5)$ or a standard mouse chow $(n=5)$. Mice fed a PGZ-supplemented diet or a standard chow and injected with corn oil served as non-fibrotic controls.

In $\mathrm{CCl}_{4}$-Balb/C mice, treatment with PGZ induced a 3-fold induction of adiponectin mRNA expression in adipose tissue $(4.39 \pm 2.21$ versus $1.19 \pm 0.7$ arbitrary units in controls; $\mathrm{p}=0.03$ ). This was paralleled by a 3 -fold increase in serum adiponectin in PGZ-treated versus untreated $\mathrm{CCl}_{4}$-Balb/C mice (Fig. 5). Administration of $\mathrm{CCl}_{4}$ to $\mathrm{Balb} / \mathrm{C}$ mice induced liver fibrosis with formation of collagen bridges between central veins (Fig. 6A). PGZ treatment did not significantly alter the severity of fibrosis induced by $\mathrm{CCl}_{4}$ as demonstrated by Sirius red staining (Fig. 6B). Moreover, the amount and distribution of activated HSCs expressing $\alpha$-SMA were not different whether $\mathrm{CCl}_{4}$-Balb/C mice were treated or not with PGZ (Fig. 6C and D). In keeping with the histological findings, hepatic hydroxyproline content (Fig. 6E) and induction of hepatic Collagen-I mRNA (Fig. 6F) were at least as high in PGZ-treated than in untreated $\mathrm{CCl}_{4}$-Balb/C mice.

To ensure that this absence of anti-fibrotic effect was not strain-dependent, we repeated the experiment on C57BL6/J mice. As in the Balb/C mice, PGZ treatment of the C57BL6/J mice induced the expression of adiponectin transcripts in adipose tissue (not shown) and circulating levels of adiponectin (Fig. 5). As reported by others (20), a similar $\mathrm{CCl}_{4}$ regimen resulted in liver fibrosis of a lesser severity in $\mathrm{C} 57 \mathrm{LB} 6 / \mathrm{J}$ than in Balb/C mice demonstrated by peri-centrolobular fibrosis with incomplete bridges (not shown), lower hepatic hydroxyproline content (Fig. 6E) and lower levels of hepatic Collagen-I mRNA (Fig. 6F). Thus, as observed in Balb/C mice, PGZ treatment did not reduce the severity of $\mathrm{CCl}_{4}$ induced fibrosis in C57BL6/J mice.

\section{Discussion}

The thiazolidinediones (TZDs), a new class of insulin sensitising anti-hyperglycemic agents, have been identified

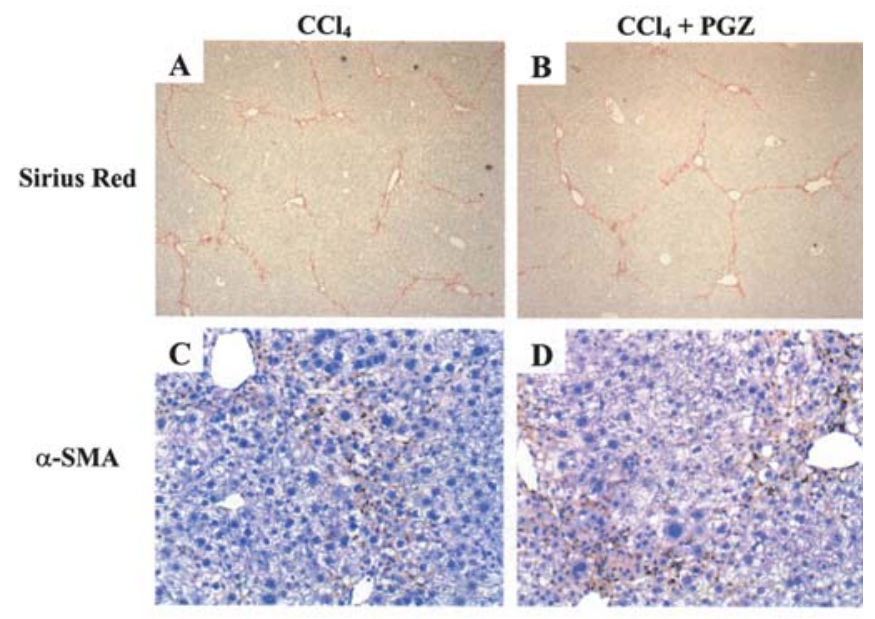

$\mathbf{E}$
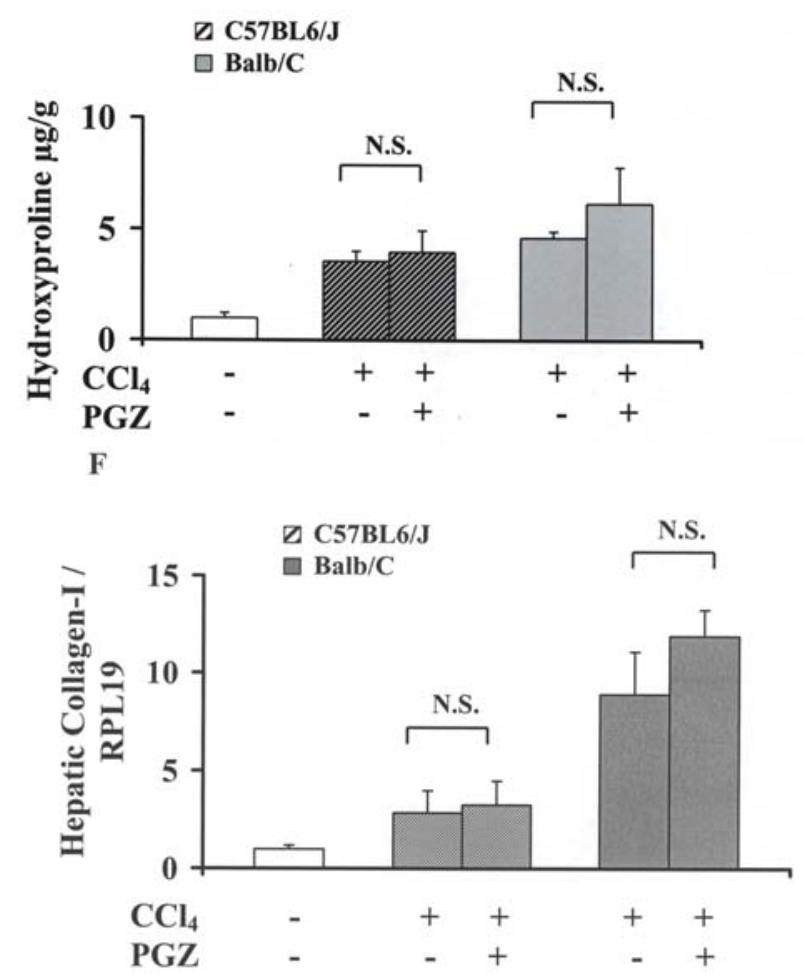

Figure 6. Effect of PGZ on hepatic fibrosis induced by $\mathrm{CCl}_{4}$ in $\mathrm{C57BL6/J}$ and $\mathrm{Balb} / \mathrm{C}$ mice. Representative photomicrographs of Sirius red-stained liver sections ( $\mathrm{A}$ and $\mathrm{B}$, collagen in red) or $\alpha$-SMA immunostained sections ( $\mathrm{C}$ and D, $\alpha$-SMA positive cells in brown) from C57BL6/J mice who received IP injections of $\mathrm{CCl}_{4}(400 \mu 1 / \mathrm{kg}$ body weight, 3 times/week for 4 weeks) and fed the control diet (A and C) or a PGZ-supplemented diet $(0.01 \% w t / w t$; B and D). Hepatic Collagen-I mRNA expression determined by real-time PCR (E) and quantification of hepatic hydroxyproline content (F) in C57BL6/J (hatched bars) and Balb/C (grey bars) mice treated with $\mathrm{CCl}_{4}(400 \mu \mathrm{l} / \mathrm{kg}$ body weight, 3 times/week for 4 weeks) and fed a PGZsupplemented diet (+) or the control diet (-). Open bars represent values obtained for the livers of untreated mice. Collagen I mRNA values were normalized to those of RPL19 regarded as an invariant control. Data are expressed as mean $\pm \mathrm{SD}$ ( $\mathrm{n}=5$ per group). N.S., the absence of statistical significance.

as high-affinity ligands for $\operatorname{PPAR} \gamma$, a nuclear hormone receptor that plays a central role as a regulator of terminal adipocyte differentiation (21). It has been shown that, in rats, TZDs significantly reduce the severity of hepatic fibrosis (7). This raises the possibility that TZDs may be used for the 
prevention and treatment of hepatic fibrosis, and as drugs of particular interest for fibrosis associated with the metabolic syndrome or non-alcoholic steatohepatitis.

Based on their studies of rat HSCs, Tsukamoto and group have proposed the concept that PPAR $\gamma$ is a key regulator of HSC biology, maintaining HSCs in their quiescent phenotype (10). In accordance with observations in rat cells (9), we found PPAR $\gamma$ protein to be expressed in quiescent primary HSCs of mouse origin. Exposure of these cells to PPAR $\gamma$ agonist PGZ activated the transcription factor as demonstrated by the induction of the PPAR $\gamma /$ PPRE binding complex by EMSA as well as by induced expression of CD36, a PPAR $\gamma$-regulated gene. As in rat cells, cultured-activation of mouse HSCs was associated with a decreased expression of PPAR $\gamma$, and their treatment with PPAR $\gamma$ ligand prevented the reduction in PPAR $\gamma$ protein expression during cultureinduced activation. Despite the presence of functional and ligand-responsive PPAR $\gamma$, the activation of this transcription factor failed to prevent, or even attenuate, the activation of mouse HSCs in vitro, as it did in rat cells $(7,9)$. Indeed, induction of Collagen-I mRNA and of $\alpha$-SMA during culture was not modified by exposure of the cells to PPAR $\gamma$ ligands PGZ or $15 \mathrm{~d}-\mathrm{PGJ}_{2}$.

In rats, two specific mechanisms have been proposed to explain the anti-fibrotic effect of PPAR $\gamma$ agonists. The first one is based on the observations that PPAR $\gamma$ expression is lost in activated HSCs and that forced expression of PPAR $\gamma$ by mean of viral transfection is sufficient to revert HSCs to their quiescent phenotype. By analogy to the adipogenic role of PPAR $\gamma$ on adipocytes, this transcription factor might thus be necessary for HSCs to retain their 'adipogenic' phenotype, which is characterized by their ability to concentrate vitamin A in lipid droplets and by their quiescence in terms of the proliferation and production of extracellular matrix. The second mechanism involves the direct participation of PPAR $\gamma$ in the transcriptional regulation of genes specific to fibrogenesis. In a recent study, Yavrom et al showed that, although no PPRE sequence was found in the promoter of the rat Collagen-I gene, PPAR $\gamma$ suppresses the proximal Collagen-I promoter via inhibition of $\mathrm{p} 300$-facilitated NF-I binding to DNA in rat HSCs (22). Our observations firmly demonstrated that ligand stimulation of PPAR $\gamma$ in mice HSCs, although having transcriptional activity, did not act as a molecular switch to prevent spontaneous activation of the cells during culture on plastic. Moreover, this transcription factor did not appear to participate in the transcriptional control of the Collagen-I gene involved in fibrogenesis. Promoter analysis will be needed to confirm this.

We show here, in two different strains of mice, that PPAR $\gamma$ agonist PGZ did not exert anti-fibrotic properties in mice in vivo. Indeed, PGZ had no impact on hepatic fibrosis, induction of hepatic Collagen-I gene expression or activation of hepatic stellate cells induced by chronic administration of $\mathrm{CCl}_{4}$. This is in sharp contrast with several reports on the anti-fibrotic properties of PPAR $\gamma$ agonist drugs in various models of fibrosis in rats $(6,7,13)$. In the literature, this antifibrotic effect has been related to inhibition of HSC activation $(7,9,13)$. Therefore, if direct regulation of HSC biology is the principal mechanism implicated in the anti- fibrotic effect of PPAR $\gamma$ agonists in rats, the absence of preventive effect of $\mathrm{PGZ}$ on hepatic fibrosis in vivo in mice is not surprising in light of our in vitro results.

A common observation in all studies published to date is that TZD treatment induces the expression of an adipocytespecific secretory protein, adiponectin (23). Adiponectin has anti-fibrotic properties. Mice lacking adiponectin are exquisitely sensitive to hepatic fibrosis while supraphysiological levels of adiponectin induced by adenovirus infection prevent $\mathrm{CCl}_{4}$-induced fibrosis in wild-type mice (24). In our study, as in similar studies in mice $(23,25)$, PGZ administered as a food mixture increased the expression of adiponectin mRNA in adipose tissue as well as serum levels of adiponectin by a factor 2 to 3 . Despite this, PGZ did not protect against fibrosis. This suggests that the rise in adiponectin levels, as obtained by PGZ treatment, is insufficient to provide protection against hepatic fibrosis. Unfortunately, the increase of PGZ doses above the therapeutic range used in this study does not further increase adiponectin levels (25). Alternatively, as PPAR $\gamma$ regulates many functions in adipocytes (24), as well as in inflammatory cells $(26,27)$, the fibro-protective properties of adiponectin may be counterbalanced by the fibro-permissive effect of other factors regulated by PPAR $\gamma$.

In summary, ligand activation of PPAR $\gamma$ by PGZ does not prevent hepatic fibrogenesis in mice. This is related to the fact that the transcription factor does not control the activation of murine HSCs nor the transcription of fibrogenic genes such as Collagen-I. In addition, the modulation of the production of adiponectin by therapeutic doses of PGZ has a negligible impact on hepatic fibrogenesis.

\section{Acknowledgments}

We thank Professor Albert Geerts, Laboratory for Molecular Liver Cell Biology, Faculty of Medicine and Pharmacy, Free University of Brussels (VUB), for the expert technical advice regarding the isolation of primary HSC; and Martine Petit et Valérie Lebrun for the technical assistance. This work was supported by a grant from the Belgian 'Fonds National de la Recherche scientifique' (FNRS convention no. 3.4507.04), by grant 05/10-328 (action de recherche concertée de la direction de la recherche scientifique de la communauté française de Belgique), and by a grant from the university (Fonds Spécial de Recherche, Université Catholique de Louvain). IL is a research associate with the FNRS.

\section{References}

1. Friedman SL: Liver fibrosis - from bench to bedside. J Hepatol 38 (suppl 1): 38-53, 2003.

2. Gressner AM: Transdifferentiation of hepatic stellate cells (Ito cells) to myofibroblasts: a key event in hepatic fibrogenesis. Kidney Int (suppl 54): 39-45, 1996.

3. Moriwaki H, Blaner WS, Piantedosi R and Goodman DS: Effects of dietary retinoid and triglyceride on the lipid composition of rat liver stellate cells and stellate cell lipid droplets. J Lipid Res 29: 1523-1534, 1988.

4. Hautekeete ML and Geerts A: The hepatic stellate (Ito) cell: its role in human liver disease. Virchows Arch 430: 195-207, 1997.

5. Friedman SL: Molecular regulation of hepatic fibrosis, an integrated cellular response to tissue injury. J Biol Chem 275: 2247-2250, 2000 
6. Marra F, Efsen E, Romanelli RG, Caligiuri A, Pastacaldi S, Batignani $\mathrm{G}$, et al: Ligands of peroxisome proliferator-activated receptor gamma modulate profibrogenic and proinflammatory actions in hepatic stellate cells. Gastroenterology 119: 466-478, 2000.

7. Galli A, Crabb DW, Ceni E, Salzano R, Mello T, Svegliati-Baroni G, et al: Antidiabetic thiazolidinediones inhibit collagen synthesis and hepatic stellate cell activation in vivo and in vitro. Gastroenterology 122: 1924-1940, 2002.

8. Spiegelman BM and Flier JS: Adipogenesis and obesity: rounding out the big picture. Cell 87: 377-389, 1996.

9. Miyahara T, Schrum L, Rippe R, Xiong S, Yee HF Jr, Motomura $\mathrm{K}$, et al: Peroxisome proliferator-activated receptors and hepatic stellate cell activation. J Biol Chem 275: 35715-35722, 2000.

10. Hazra S, Miyahara T, Rippe RA and Tsukamoto H: PPAR gamma and hepatic stellate cells. Comp Hepatol 3 (suppl 1): 7, 2004.

11. Hazra S, Xiong S, Wang J, Rippe RA, Krishna V, Chatterjee K, et al: Peroxisome proliferator-activated receptor gamma induces a phenotypic switch from activated to quiescent hepatic stellate cells. J Biol Chem 279: 11392-11401, 2004.

12. She H, Xiong S, Hazra S and Tsukamoto $\mathrm{H}$ : Adipogenic transcriptional regulation of hepatic stellate cells. J Biol Chem 280: 4959-4967, 2005 .

13. Kon K, Ikejima K, Hirose M, Yoshikawa M, Enomoto N, Kitamura T, et al: Pioglitazone prevents early-phase hepatic fibrogenesis caused by carbon tetrachloride. Biochem Biophys Res Commun 291: 55-61, 2002.

14. Leclercq IA, Sempoux C, Starkel P and Horsmans Y: Limited therapeutic efficacy of pioglitazone on progression of hepatic fibrosis in rats. Gut 55: 1020-1029, 2006.

15. Moore KJ, Rosen ED, Fitzgerald ML, Randow F, Andersson LP, Altshuler D, et al: The role of PPAR-gamma in macrophage differentiation and cholesterol uptake. Nat Med 7: 41-47, 2001.

16. Geerts A, Eliasson C, Niki T, Wielant A, Vaeyens F and Pekny M: Formation of normal desmin intermediate filaments in mouse hepatic stellate cells requires vimentin. Hepatology 33: 177-188, 2001.

17. Colin IM, Nava E, Toussaint D, Maiter DM, Vandenhove MF, Luscher TF, et al: Expression of nitric oxide synthase isoforms in the thyroid gland: evidence for a role of nitric oxide in vascular control during goiter formation. Endocrinology 136: 5283-5290, 1995.
18. Starkel P, Sempoux C, Leclercq IA, Herin M, Deby C, Desager JP, et al: Oxidative stress, KLF6 and transforming growth factor-beta up-regulation differentiate non-alcoholic steatohepatitis progressing to fibrosis from uncomplicated steatosis in rats. J Hepatol 39: 538-546, 2003.

19. Leclercq IA, Farrell GC, Schriemer R and Robertson GR: Leptin is essential for the hepatic fibrogenic response to chronic liver injury. J Hepatol 37: 206-213, 2002.

20. Shi Z, Wakil AE and Rockey DC: Strain-specific differences in mouse hepatic wound healing are mediated by divergent T helper cytokine responses. Proc Natl Acad Sci USA 94: 10663-10668, 1997.

21. Lehmann JM, Moore LB, Smith-Oliver TA, Wilkison WO, Willson TM and Kliewer SA: An antidiabetic thiazolidinedione is a high affinity ligand for peroxisome proliferator-activated receptor gamma (PPAR gamma). J Biol Chem 270: 12953-12956, 1995.

22. Yavrom S, Chen L, Xiong S, Wang J, Rippe RA and Tsukamoto H: Peroxisome proliferator-activated receptor gamma suppresses proximal alpha1(I) collagen promoter via inhibition of $\mathrm{p} 300-$ facilitated NF-I binding to DNA in hepatic stellate cells. J Biol Chem 280: 40650-40659, 2005.

23. Combs TP, Wagner JA, Berger J, Doebber T, Wang WJ, Zhang BB, et al: Induction of adipocyte complement-related protein of 30 kilodaltons by PPAR gamma agonists: a potential mechanism of insulin sensitization. Endocrinology 143: 998-1007, 2002.

24. Kamada Y, Tamura S, Kiso S, Matsumoto H, Saji Y, Yoshida Y, et al: Enhanced carbon tetrachloride-induced liver fibrosis in mice lacking adiponectin. Gastroenterology 125: 1796-1807, 2003.

25. Kubota N, Terauchi Y, Kubota T, Kumagai H, Itoh S, Satoh H, et al: Pioglitazone ameliorates insulin resistance and diabetes by both adiponectin-dependent and -independent pathways. J Biol Chem 281: 8748-8755, 2006.

26. Jiang C, Ting AT and Seed B: PPAR-gamma agonists inhibit production of monocyte inflammatory cytokines. Nature 391: 82-86, 1998

27. Ricote M, Li AC, Willson TM, Kelly CJ and Glass CK: The peroxisome proliferator-activated receptor-gamma is a negative regulator of macrophage activation. Nature 391: 79-82, 1998. 